\title{
Decentralized Health System Leadership: Are District Health Management Teams in Good Hands? Perspectives of 4 districts in Sierra Leone
}

\author{
Alhassan Fouard Kanu \\ Email: allanzain2009@yahoo.co.uk
}

\begin{abstract}
Background: Evidence is abound that good leadership and management practices can improve the performance of health system Conversely, poor leadership practices from health leaders have detrimental effects on the performance of the health system. Decentralized district health system is the cornerstone of a country's health sectors. This is the more the reason the post Ebola health system strengthening in Sierra Leone had a component on staff leadership development for personnel at both central and district levels. In this study, the leadership styles of the District Medical Officers (DMOs) are examined to assess their influence on the performance of DHMTs in Sierra Leone.

Methods: The was a cross-sectional quantitative study that targeted the heads of units within the District Health Management Teams of Bo, Kailahun, Kenema, and Kono. A self-administered questionnaire using Likert Scale was provided to the subordinates $(n=23)$ to rate the leadership and management practices of their DMOs. SPSS version 25 was used to analyze the data.

Results: The leadership and management practices of the DMOs are rated as democratic by the majority of the subordinates. However, the subordinates also reported that their DMOs are domineering and are also encouraging favouritism within the teams. The study did not find any statistically significant difference among the four districts on the influence of leadership of the DMO and DHMT performance $(p>.05)$.

Conclusions: The leadership style of the health managers can influence the performance of the DHMT. In this study, the leadership style of the DHMTs is largely perceived to be democratic by their subordinates. The good leadership skills of the DMOs in the surveyed districts might be responsible for the relative effectiveness and efficiency of the operations of their DHMTs. However, the majority of the subordinates in all the districts testified that their DMOs are domineering and also encourage favouritism. These practices are considered autocratic and divisive. These are areas for the MoHS leadership to actually examine and address for optimal DHMT performance. Keywords: healthcare, leadership styles, management and leadership theories, health system, health system strengthening, health system performance, district health system, district health management, decentralization, and devolution
\end{abstract}

DOI: $10.7176 / \mathrm{JHMN} / 76-02$

Publication date:June 30th 2020

\section{Introduction}

The health of the citizens in any country is critical for population and economic growth; and this is probably the reason why health is considered as a public good. The health needs of the people are addressed through the health system. The main objective of the health system is to ensure accessible, equitable, and safe delivery of health services (Panda, Thakur \& Zodpey, 2016). In other words the health system should be responsive to the health needs of the population regardless of age, gender, race among other socio-demographic variables. Globally, efforts towards strengthening health services are considered very important in ensuring improved population health outcomes (Panda, Thakur \& Zodpey, 2016).

Low- and middle-income countries (LMICs) have weak health systems due to under-funding, poor health governance and inadequate numbers of competent health personnel. Whilst there are structural factors that undermine the overall health systems performance in LMICs, it is also clear that strong health systems governance and stewardship can promote effective and efficient health service delivery. Evidence is abound that effective leadership and management can influence the relative performance of health systems (O'neil, 2008; Curry et al., 2012). Driving health systems performance requires effective leaders as well as an enabling environment. The role of the health leaders is very critical for an effective health service delivery. Bradley et al. (2015) note that health leaders are expected to give direction to the health teams, managing other resources, as well as galvanizing the support and commitment of the broad stakeholders in driving the health agenda. The health manager should be able to drive change and promote better ways of delivering responsive and efficient health services to the public through an effective deployment of resources including healthcare staff (Prashanth et al., 2014, Tetui et al., 2017). Good management practices have been linked to higher overall performance of the health sector, leading to greater patient satisfaction and lower patient mortality (Nzinga, Mbaabu, \& English, 2013; WHO, 2007). Health managers' leadership style is therefore critical on the effectiveness of staff. Where the manager's leadership style is 
destructive, it could render the team ineffective and undermine performance.

Decentralizing decision making to sub-national levels is considered as an important element in the management of development process. This is probably the reasons why decentralization has been recognized as very key in the implementation of primary health care services (WHO, 1988). Conn et al (1996) explain managers tend to be more effective if they have the autonomy to control their resources and activities. These managers inherently would be in a better position to reflect on the health needs of their local communities as they plan and prioritize funding for essential health interventions as well as to be able to advocate for additional resources from potential funders, including their national governments (Bossert et al., 1991). In 2004, the Government of Sierra Leone introduced decentralization of ministries, departments and agencies. The health sector has since become a decentralized function of the local government. The governance of the health sector and the delivery of health services are currently decentralized; with national level responsible for the development of policies and strategies; whilst the sub-national level, through the DHMTs are responsible for the implementation of strategies and policies developed by programs and directorates at the national level.

In resource-constraint settings such as Sierra Leone and other low-income countries, the management capacity of health managers is critical to ensure an efficient use of the scarce resources to attain or improve population health outcomes (Koplan et al., 2009). This is more the reason why investments in efforts to improve the management capacity of health managers is considered very strategic as it will facilitate the achievement of large ends with limited means (Curry et al., 2010). In the era of healthcare decentralization, more responsibilities are given to district health systems to implement national health priorities. Further, the district health system is expected to drive intersectoral collaboration in service delivery including managing the work of other stakeholders in health such as NGOs and CBOs. It requires thus that, the health managers at district level should have management capacity to drive the health agenda. The complexity of hospitals and the routine management of the operations of lower level health facilities require strategic focus to maximize community and patients benefits given the scare resources. Furthermore, evidence have pointed out that, both staff motivation and retention can be influenced by the quality of management in their work setting (Jack et al., 2013; Chimwaza et al., 2014). Nevertheless, management education, especially in LMIC is very limited in medical and public health training; rather it is reserved for business curricula (Bradley, Taylor \& Cuellar, 2015); and this has negative implications on the management of healthcare services. Good management is fundamental not only for business and private sectors but also for the health sector. This is however been overshadowed by the more visible clinical roles in healthcare organizations. Studies have consistently observed that, the success of any organization is contingent upon the manner in which the leader operates (Jack et al., 2013; Chimwaza et al., 2014; Bradley, Taylor \& Cuellar, 2015). The leadership style of those at the helm of an organization has a critical role in the success of the organization. In healthcare, an effective leadership style can lead to the attainment of health system goals and objectives. It is suffice then to state that, the success of the health system largely depends on the ability of the health managers using a specific or blend of leadership styles as the situation dictates.

Sierra Leone, as one of the three (3) Mano River Union Ebola viral disease (EVD) affected countries in West Africa in 2014 attributed the weak health system infrastructure and capacity as the principal reasons for the rapid spread of the outbreak (Elston et al., 2015; MoHS, 2015). As part of the response and recovery efforts, a range of health systems strengthening initiatives were instituted to strengthen the country's health system. Some of the initiatives including staff development across a range of discipline, including health system leadership and management. These initiatives are expected to enable the health sector to withstand future health shocks, as well as improving the health outcomes of the population. Studies and evaluations have been conducted previously to examine health system challenges but little is known on the contributions of DMOs' leadership and management practices to the overall performance of the district health management team (DHMT). In this study, the leadership styles of the District Medical Officers (DMOs) are examined to assess their influence on the performance of DHMTs in Sierra Leone. The findings of the study will contribute towards the designing of systems and programmes to improve district health leadership, which by extension will improve the performance of DHMTs and population health outcomes in Sierra Leone.

\section{Leadership styles}

As the literature has suggested, leadership is probably the most widely studied topic in the field of organizational sciences and management supported with a variety of theories. Leadership theories are commonly categorized into trait, behavioral, contingency, and influence or power approaches (Northouse, 2010). This study focuses on leadership styles of District Medical Officers and their influence of the performance of the DHMT and as such will not attempt to elaborate on the leadership theories.

Evidence in the literature supports a theory that in healthcare settings, a manager's leadership style may affect the job satisfaction of the employees (AL Hussami, 2008; Cullen \& Gordon, 2014). This review will highlight earlier described leadership styles (autocratic, democratic and laissez-faire) that will be considered in the current study. 
Leadership style has been defined as the pattern or behaviour that characterize a given leader. It can be said, leaders often adopt a particular behaviour or style that would enable them to succeed in their roles. The success of any organization is highly influenced by the type of leadership. The role of the leader is basically to influence personnel within his/her jurisdiction to strive willingly and enthusiastically towards the accomplishment of organizational goals and objectives (Ezenwai, 2005). The inherent truth is that, a leader cannot work alone but with others who might have diverse contributions to the organizational goals. This underscores the importance of the leader's ability to influence others without threat or violence towards the attainment of goals and objectives as set-out by the organization. It requires thus that, a leader employs a specific leadership style or a combination of leadership styles, as the situation demands, in order to influence the cooperation of individuals within a team to execute tasks effectively.

Shamaki (2015) and Ozuruoke et al. (2011) summarized the earlier described three leadership styles in the literature (autocratic, democratic, and laissez-faire) as follow:

Autocratic leadership style: the type of leadership is also widely referred to as authoritarian style of leadership. Autocratic leaders hold all the powers of decision-making and often do not consult others; rather the leader only directs team members on the ways things should be done. In this environment, there is always a lack of clear channel of communication between the leader and the group members as the power of decision-making entirely resides on the autocratic leader. The implications for this type of leadership is that, group members are stifled and become less creative since they lack the opportunity to be heard in decision-making within the organization; and this often leaves them disempowered and dissatisfied.

Democratic leadership style: Democratic leadership style is also referred to as consultative leadership style. Leaders with this style of leading engage group members within the organization in the process of decision-making. They recognize every member within their teams as valuable partner whose views matter in making decisions that affect the team and the organization. Communication is multi-directional wherein there is a free exchange of ideas between the subordinates and the leader. This style of leadership enhances a high degree of morale within the team, and ultimately could positively affect the performance of the organization.

Laissez-faire leadership style: In this style of leadership, subordinates are usually free to do what they want. In essence, the group members have total control on group decision-making without the participation of the leader. Others have criticized this style of leading. Shamaki (2015) suggests this style predisposes to unproductive activities that could be adversely detrimental to both the organization and group members.

The role of leaders in any organization is critical to its success. The leaders are simply the means to an end; and they can adopt a single or a combination of leadership styles depending on the context and circumstances at a particular given time. However, many authors have argued that, democratic leadership style is the best in driving effective and efficient operations in an organization (Shamaki, 2015). This style of leadership cares both for the welfare of the people within the organization and organizational performance.

Many studies have revealed a positive relationship between a manager's leadership style and employee satisfaction levels and motivation (Bass \& Avolio, 1985; Al-Yamin, Galda \& Watson, 2017; Musinguzi et al., 2018; Mulengo, Nzala, \& Mutale, 2018). Alloubani et al (2014) have reported that, the relationship between leadership styles and employee motivation and satisfaction is positively associated with both the organization and patient outcomes. This study uses autocratic and democratic leadership style for hypothesis testing.

\subsection{Materials and Methods}

This is a cross-sectional quantitative study aims at understanding the extent to which leadership styles of the DMOs among other inherent factors can influence the subordinates' performance and ultimately the performance of the DHMTs in Sierra Leone.

\section{Research Participants}

The target participants for this study were members of the DHMT. To be included in the study, participants must be members of the team; serving a minimum of 1 year as head of a unit or focal person. Members who have spent less than a year and are not heading units within the DHMT are excluded from the study. The study also excluded the District Medical Officers.

\section{Sampling of the participants}

The study considered heads of units at the DHMT. The participants were selected, using a non-probabilistic purpose sampling. The targeted participants are heads of strategic units within the DHMT because of their knowledge on the operations of the DHMT; and hence, can provide the needed information to discern the factors that influence the performance of the DHMT. In this study, a total of six (6) heads of the most strategic units in the operations of the DHMT were selected in each district. These are: (1) District Health Sister; (2) Monitoring \& Evaluation (M\&E) Officer; (3) Human Resources Officer; (4) District Logistics Officer; (5) Disease Surveillance Officer; and (6) Finance Officer. The study therefore targeted a total of 24 DHMT officials in the four districts 
that participated in the study.

\section{Study Setting}

There are 16 DHMTs in Sierra Leone representing the 16 health districts in the country. For this study, only four (4) districts (Bo, Kailahun, Kenema, and Kono), drawn from 2 (Eastern and Southern Provinces) of the 4 regions in the country were purposively selected. These districts represent both high performing and low performing districts in the MoHS 2018 integrated supportive supervision (MoHS, 2018). The choice of both high and low performing districts will provide insights on whether the leadership style and management practices of the DMOs play a significant role in the performance of the DHMTs in Sierra Leone.

\section{Data Collection Procedures}

A semi-structured questionnaire was used to obtain pertinent information from the selected DHMT members on the leadership style of their DMOs and it relation to the performance of the DHMT. The questionnaire was on the leadership and management practices of the DMO. It was a participant's self-assessment of his or her supervisor's (i.e. the DMO) leadership style. The questionnaire was designed with a focus on democratic and autocratic leadership attributes. It contains 20 items and respondents were instructed to rate their DMOs. Likert scale with four points, from strongly agree (SA) to strongly disagree (SA), was used to generate information on the influence of DMOs leadership styles on staff's job productivity; and ultimately DHMT performance.

Prior to conducting the interviews, the heads of the DHMT i.e. the District Medical Officers (DMO) were contacted to discuss the purpose of the study and to seek their consent for the study to be conducted within their teams. Further, the targeted respondents within the respective DHMTs were contacted to seek their willingness to participate after they have read and understood the study information sheet. The self-administered questionnaires were given to the participants with an agreement to return the completed questionnaire within 72 hours. The data collection process lasted for a period of one month (April-May 2019).

\section{Data Processing and Analysis}

The analysis of the survey data uses both descriptive and inferential analysis; using SPSS version 25 . The descriptive analysis includes computing of total score for all items representing each variable. The descriptive statistics is presented using tables and charts. For the inferential analysis, Chi-square test was used to test the hypothesis on whether there is a significant difference between the performance of DHMT under a democratic DMO and the performance of DHMT under an autocratic DMO.

\section{Ethical Considerations}

Data collection commenced after review and approval of research protocols by the Sierra Leone Ethics \& Scientific Review Committee (SLESRC). Participants were not forced to participate and were given the right to withdraw from the study at any stage of the interview without prejudice or penalty. To ensure anonymity, each study participant was assigned a code that corresponded with his or her DHMT and only placing the participant's number on the questionnaire, scoring, and code sheets.

\section{Results}

The study targets a total of 24 participants ( 6 participants in each district) in the 4 districts of Bo, Kailahun, Kenema, and Kono. The study response rate was $96 \%$ (23 out of 24 participants). The missing participant was due to eligibility reason, as the staff is newly transferred to one of the DHMT and failed to meet the criteria of a minimum 1 year with the DHMT.

\section{Characteristic of the participants}

Table 1 provides the background of the participants. The majority of the participants are male, accounting for $74 \%$ $(n=17)$ of the participants. Most of the study participants are in the age bracket $36-45$ years, accounting for $48 \%$ $(n=11)$ of the participants. With regards the highest level of education, only 4 out of 23 participants have postgraduate degrees. Majority of the participants $(43 \%)$ are certificate and diploma holders in different professional areas such community/public health, finance, logistics, and pharmacy; whilst $39 \%$ have bachelor's degrees. On the length of service in the Ministry of Health \& Sanitation, nearly half of the participants (43\%) have spent 6-10 years in the organization. 
Table 1: Background of Study Participants

\begin{tabular}{|c|c|}
\hline Characteristics & $\begin{array}{c}\text { Participants } \\
\text { n (\%) }\end{array}$ \\
\hline GENDER Male & $17(74)$ \\
\hline Female & $6(26)$ \\
\hline AGE & $6(26)$ \\
\hline $26-35$ & $11(48)$ \\
\hline $36-45$ & $6(26)$ \\
\hline $46-55$ & \\
\hline HIGHEST LEVEL OF EDUCATION & $10(43)$ \\
\hline Certificate/Diploma & $9(39)$ \\
\hline Bachelors & $4(17)$ \\
\hline Masters & \\
\hline YEARS OF EMPLOYMENT & $7(30)$ \\
\hline $1-5$ years & $10(43)$ \\
\hline 6-10 years & $2(9)$ \\
\hline $11-15$ years & $2(9)$ \\
\hline 16 -20 & $2(9)$ \\
\hline 20 years and above & \\
\hline
\end{tabular}

DMO leadership and management practices

To examine the role of the DMO's leadership style on staff's job productivity and the DHMT performance, a participant self-administered questionnaire was used in which respondents were instructed to rate their DMOs. The questionnaire was designed with a focus on democratic and autocratic leadership attributes; focusing only on the subordinate staff. Ten of the commonest leadership and management practices that can influence personal and team performance were examined, using a bivariate analysis, to determine if there is any significant difference in DMOs' leadership styles among the districts.

As shown in table 4 below, $15(65 \%)$ of the 23 subordinates strongly agreed/agreed that their DMOs are domineering. Also, 13 (57\%) of the participants agreed that their DMOs encourages favouritsm in their teams. Both of these leadership behaviours are indicators of autocratic leadership practices with dire consequences on the cohesion and performance of the DHMTs. However, $78 \%(n=18)$ of the participants disagreed that, the DMOs do not entertain advice from the team. The rest of the attributes, which are considered as democratic leadership practices were strongly agreed/agreed by the majority of the subordinates as being practiced by their DMOs. There is no statistically significant difference among the four districts on the leadership and management practices of the DMOs $(p>.05)$. This suggest that, there is no statistically significant difference between the DMO leadership style and the performance of the DHMT. 
Table 4: Bivariate Analysis on DMOs' leadership styles

\begin{tabular}{|c|c|c|c|c|c|c|c|c|c|}
\hline \multirow{2}{*}{ Statements } & \multirow{2}{*}{ Responses } & \multicolumn{4}{|c|}{ DHMT vs Participants' responses } & \multirow{2}{*}{ Totals } & \multirow{2}{*}{$\begin{array}{l}\text { Chi- } \\
\text { Square }\end{array}$} & \multirow{2}{*}{ df } & \multirow{2}{*}{$P$-value } \\
\hline & & Bo & Kailahun & Kenema & Kono & & & & \\
\hline \multirow{4}{*}{$\begin{array}{l}\text { DMO is } \\
\text { domineering }\end{array}$} & Strongly Agree & 3 & 3 & 1 & 1 & 8 & \multirow{4}{*}{8.796} & \multirow{4}{*}{9} & \multirow{4}{*}{$p>.05$} \\
\hline & Agree & 1 & 1 & 4 & 1 & 7 & & & \\
\hline & Disagree & 2 & 1 & 0 & 2 & 5 & & & \\
\hline & Strongly Disagree & 0 & 1 & 1 & 1 & 3 & & & \\
\hline \multirow{4}{*}{$\begin{array}{l}\text { DMO delegates } \\
\text { authority to staff }\end{array}$} & Strongly Agree & 3 & 2 & 3 & 1 & 9 & \multirow{4}{*}{4.928} & \multirow{4}{*}{6} & \multirow{4}{*}{$p>.05$} \\
\hline & Agree & 2 & 4 & 3 & 4 & 13 & & & \\
\hline & Disagree & 1 & 0 & 0 & 0 & 1 & & & \\
\hline & Strongly Disagree & 0 & 0 & 0 & 0 & 0 & & & \\
\hline \multirow{4}{*}{$\begin{array}{l}\text { DMO encourages } \\
\text { favouritism in the } \\
\text { team }\end{array}$} & Strongly Agree & 3 & 2 & 0 & 0 & 5 & \multirow{4}{*}{8.178} & \multirow{4}{*}{9} & \multirow{4}{*}{$p>.05$} \\
\hline & Agree & 2 & 1 & 3 & 2 & 8 & & & \\
\hline & Disagree & 1 & 1 & 1 & 1 & 4 & & & \\
\hline & Strongly Disagree & 0 & 2 & 2 & 2 & 6 & & & \\
\hline \multirow{4}{*}{$\begin{array}{l}\text { DMO allows staff } \\
\text { decision-making }\end{array}$} & Strongly Agree & 2 & 1 & 1 & 1 & 5 & \multirow{4}{*}{5.316} & \multirow{4}{*}{6} & \multirow{4}{*}{$p>.05$} \\
\hline & Agree & 2 & 5 & 4 & 4 & 15 & & & \\
\hline & Disagree & 2 & 0 & 1 & 0 & 3 & & & \\
\hline & Strongly Disagree & 0 & 0 & 0 & 0 & 0 & & & \\
\hline & Strongly Agree & 3 & 2 & 1 & 1 & 7 & & & \\
\hline DMO has good & Agree & 2 & 2 & 4 & 4 & 12 & 4874 & 6 & $n>05$ \\
\hline rapport with staff & Disagree & 1 & 2 & 1 & 0 & 4 & 4.014 & 0 & $p=0.0$ \\
\hline & \begin{tabular}{|l|} 
Strongly Disagree \\
\end{tabular} & 0 & 0 & 0 & 0 & 0 & & & \\
\hline & Strongly Agree & 2 & 1 & 1 & 1 & 4 & & & \\
\hline DMO commends & Agree & 2 & 4 & 4 & 5 & 15 & 7283 & 9 & $n>05$ \\
\hline staff effort & Disagree & 1 & 1 & 1 & 0 & 3 & 1.203 & 3 & S \\
\hline & Strongly Disagree & 1 & 0 & 0 & 0 & 1 & & & \\
\hline & Strongly Agree & 0 & 1 & 0 & 0 & 1 & & & \\
\hline DMU encourages & Agree & 5 & 4 & 5 & 2 & 16 & 6612 & 6 & $n>05$ \\
\hline staff & Disagree & 1 & 1 & 1 & 3 & 6 & 0.015 & 0 & $p=.05$ \\
\hline & Strongly Disagree & 0 & 0 & 0 & 0 & 0 & & & \\
\hline & Strongly Agree & 1 & 1 & 1 & 0 & 3 & & & \\
\hline DNO thoroughly & Agree & 5 & 3 & 5 & 3 & 16 & 500 & 0 & $n>05$ \\
\hline of the DHMT & Disagree & 0 & 1 & 0 & 1 & 2 & 3.99 & 9 & $p=.05$ \\
\hline & Strongly Disagree & 0 & 1 & 0 & 1 & 2 & & & \\
\hline DMO gives moral & Strongly Agree & 1 & 2 & 0 & 1 & 4 & & & \\
\hline and financial & Agree & 4 & 2 & 5 & 2 & 13 & 4526 & 6 & $n>05$ \\
\hline support where & Disagree & 1 & 2 & 1 & 2 & 6 & & & \\
\hline necessary & Strongly Disagree & 0 & 0 & 0 & 0 & 0 & & & \\
\hline & \begin{tabular}{|l|} 
Strongly Agree \\
\end{tabular} & 0 & 0 & 1 & 0 & 1 & & & \\
\hline entertain advice & Agree & 1 & 1 & 0 & 2 & 4 & 5.832 & 6 & $p>.05$ \\
\hline entertain advice & Disagree & 4 & 4 & 4 & 2 & 14 & & & \\
\hline & Strongly Disagree & 1 & 1 & 1 & 1 & 4 & & & \\
\hline
\end{tabular}

Effect of DMOs Leadership Styles on DHMT Performance

Subordinates responded to a statement on whether the leadership style of the DMO has a positive effect on the performance of the DHMT. As shown in figure 1 below, 74\% $(n=17)$ of the participants agreed that, the leadership style of their DMO has a positive effect on the DHMT performance; whilst $26 \%(n=6)$ of the participants disagreed. 


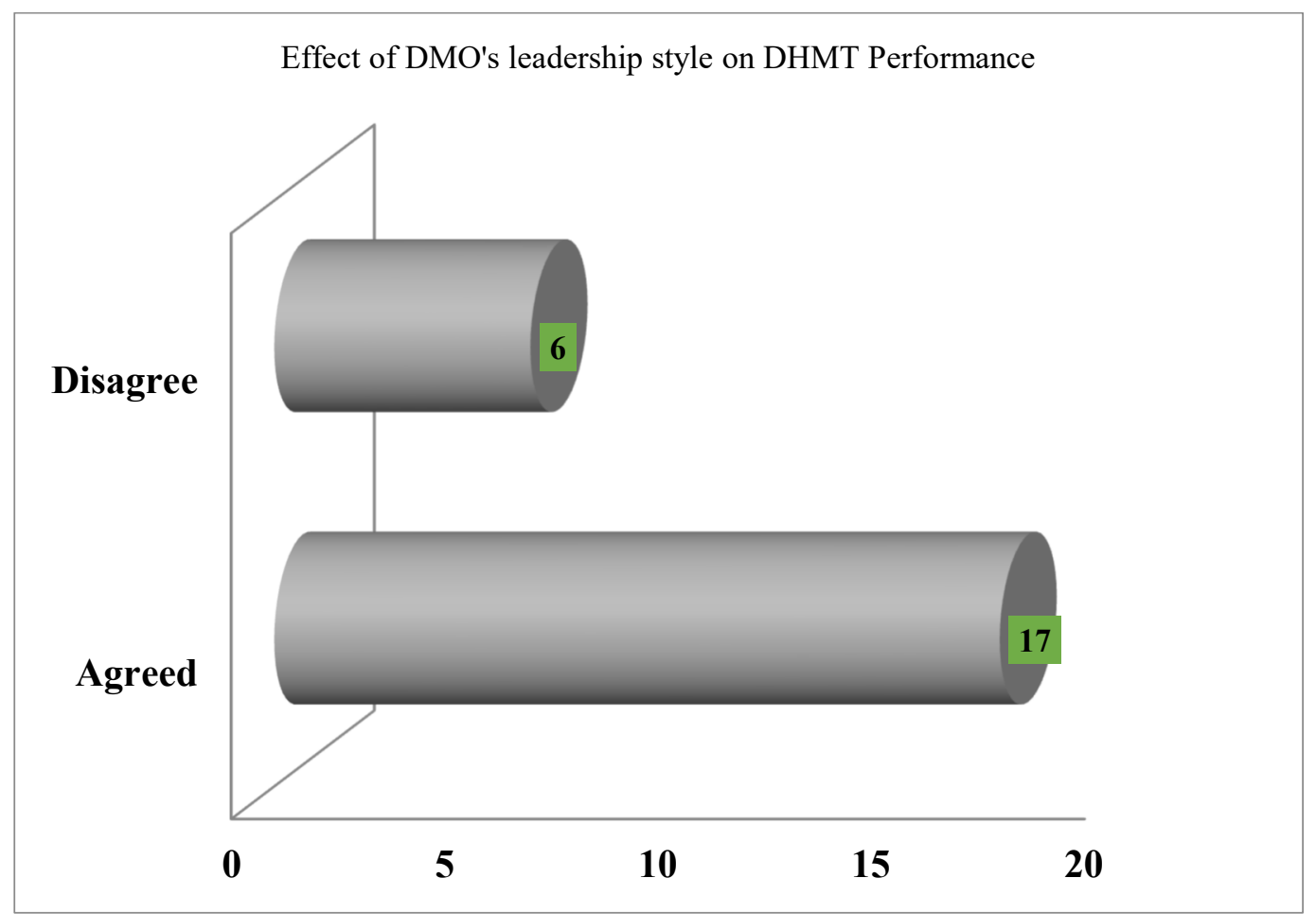

Figure 1: Subordinates' perception on the positive effects of DMO's leadership on DHMT performance

Another statement attempted to explore whether the subordinates are satisfied with the performance of their DHMTs in relation to the leadership style of the DMO. As seen in figure 62 below, $70 \%$ and 30\% indicated that they are "Happy" and "Not Happy" with the performance of their DHMTs respectively.

\section{Level of satisfaction}

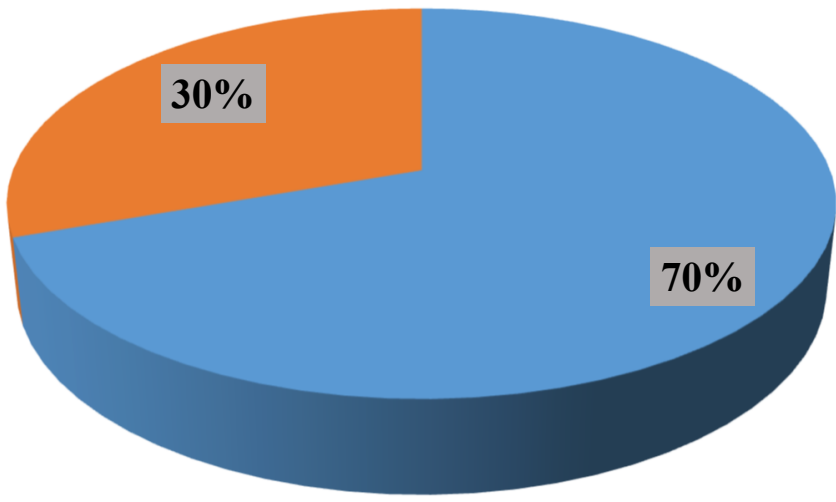

- Happy with perfromance

Not Happy with performance

Figure 2: Participants' opinions on the performance of the DHMT

The job productivity of an individual staff can be influenced by the working environment. A statement was posed to the subordinates on their views on whether the present working condition is encouraging in terms of internet availability, power supply, office space and sitting accommodation among other considerations. As indicated in figure 3 below, $65 \%(n=15)$ of the respondents disagreed on the statement; a testament that their working conditions are poor. There is a statistically significant difference on the working conditions in the various districts, $\chi^{2}(3, N=23)=8.453, p=.038$. One of the district had 5 of the 6 staff agreed on having an encouraging working condition; whilst the majority in the other districts disagreed.

\section{Discussions, Conclusions and Recommendation}

The leadership styles of health managers have been documented as a critical factor in the success of healthcare 
teams and organizations (O'neil, 2008; Curry et al., 2012). In the current study, the desired leadership was democratic leadership style which according to many studies have been reported to positively influence team performance (Shmaki, 2005; Ozuruoke et al., 2011). The findings of the study revealed that, most of the DMOs practiced democratic leadership style as testified by their subordinates. The study findings indicate that, the good leadership skills of the DMOs support the relative efficiency and effectiveness of the DHMT. The findings of the current study support those of Mkoka et al. (2014) where good leadership skills of the health managers were recognized for the successful implementation of EmOC services in Tanzania. The study also found some autocratic leadership practices. Over half of the subordinates agreed that, their DMO's where domineering; as well as entertaining favouritism within the DHMTs. The subordinates' perceptions of their DMOs as entertaining favoritism may not be unconnected to earlier findings. According to Kanu (2020), DMOs in the studied districts reported that, some of the staff lack the basic competencies, including computer skills to execute tasks effectively and timely. As a result, the DMOs become closer to members of the team that are more cooperative and with the required competencies and attitude. The study found no statistically significant difference among the districts on the influence of the DMOs' leadership styles on the performance of the DHMTs. This demonstrates that, the influence of DMO leadership styles on the performance of DHMT does not differ between districts. It suggests also that, the performance of a DHMT has no significant relationship with the leadership style of the DMO; rather on other factors as responsible for DHMT performance. The findings of the current study differ from those by Maluka (2013). Maluka explored why are pro-poor exemption policies in Tanzania were better implemented in some districts than in others? The author concluded that, the management and leadership practices of the district health leaders, among other factors, were largely responsible for the difference in the implementation between districts. In the current study however, the majority of the subordinates considered the leadership styles of the DMOs as having positive influence on the performance of the DHMT.

The job productivity of an individual staff can be influenced by the working environment. The responses of the subordinates on the statement regarding how encouraging is there working present conditions, majority testified that, the working environment is poor.

\section{Conclusions}

The leadership style of the health managers can influence the performance of the DHMT. In this study, the leadership style of the DHMTs is largely perceived to be democratic by their subordinates. The good leadership skills of the DMOs in the surveyed districts might be responsible for the relative effectiveness and efficiency of the operations of their DHMTs. However, the majority of the subordinates in all the districts testified that their DMOs are domineering and also encourage favouritism. These practices are considered autocratic and divisive. These are areas for the MoHS leadership to actually examine and address for optimal DHMT performance. The MoHS should introduce proper leadership and management orientation for district health leaders including the DMOs and Medical Superintendents prior to taking up their posts. Such orientation is also important for every personnel that will be managing staff in every level of the healthcare delivery system.

\section{Study Limitations}

The study focuses only on democratic and autocratic leadership styles and this was reflected in the research questionnaire. The prevalence of other leadership styles such as laissez-faire was not captured. The sampling of participants was purposive, considering only the most relevant members of the DHMTs. The other members would have had the opportunity to participate in the study if a random sampling technique was applied for the entire team members.

\section{Acknowledgement}

My thanks go to the District Health Sisters, District M\&E Officers, District Finance Officers, District Human Resources Officers, and District Surveillance Officers of Bo, Kailahun, Kenema, and Kono districts for participating in the study. Thanks to the DMOs of these districts for their support.

\section{References}

AL-Hussami, M. (2008). 'Study of nurse's job satisfaction: The relationship to organizational commitment, perceived organizational support, transactional leadership, transformational leadership, and level of education'. European Journal of Scientific Research, 22, 286-295.

Al-Yamin, M., Galdas, P., \& Watson, R. (2017). 'Leadership style and organizational commitment among nursing staff in Saudi Arabia'. Journal of Nursing Management;26,pp.531-539.

Bass, B. M. (1985). Leadership and performance beyond expectation. New York, NY:Free Press.

Bossert, T., Soebekti, R., \& Aria, N.K.(1991). 'Bottom-up planning in Indonesia: Decentralisation in the ministry of health'. Health Policy and Planning 6,pp.55-63

Bradley, E.H., Taylor, L.A., \& Cuellar, C.J. (2015). 'Management Matters: A Leverage Point for Health Systems 
Strengthening in Global Health'. International Journal of Health Policy \& Management, 4(7), pp. 411 - 415. doi: 10.15171/ijhpm.2015.101

Chimwaza, W., Chipeta, E., Ngwira, A. et al. (2014). 'What makes staff consider leaving the health service in Malawi?' Human Resources for Health;12:17. doi:10.1186/1472-6963-8-247

Cometto, G., \& Campbell, J.(2016). 'Investing in human resources for health: Beyond health outcomes'. Human Resource Health; 14:51, pp.1-2.

Conn, C.P., Jenkins, P., \& Touray, S.O. (1996). 'Strengthening health management: Experience of district teams in The Gambia'. Health Policy and Planning; 11(1): pp. 64-71

Cullen, C., \& Gordon, P. (2014). 'The relationship between leadership and communication skills of nurse managers and the organizational citizenship behaviors of medical-surgical nurses and nursing assistants'. Management and Organizational Studies, 1(2), pp.23-29. doi:10.5430/mos.v1n2p23

Curry, L., Taylor, L., Chen, P.G., \& Bradley, E. (2012). 'Experiences of leadership in health care in sub-Saharan Africa'. Human Resources for Health, 10(33), pp.1-8

Elston, J.W.T., Moosa, A.J., Moses, F., Walker, G., Dotta, N., Waldman, R.J., \& Wright, J.(2015). 'Impact of the Ebola outbreak on health systems and population health in Sierra Leone'. Journal of Public Health, 38(4), pp. 673-678. doi:10.1093/pubmed/fdv158

Ezeuwo (2005). Isues in educational management . Enugu.Hipuks additional press.

Jack, H., Canavan, M., Ofori-Atta, A., Taylor, L., \& Bradley, E.(2013). 'Recruitment and retention of mental health workers in Ghana'. PLoS One.;8(2):e57940. doi:10.1371/journal.pone.0057940

Kanu, A.F. (2020). Exploring the factors Influencing the Performance of District Health Management Teams in Sierra Leone. Journal of Health, Medicine and Nursing. (Paper accepted and awaiting publication). DOI: 10.7176/JHMN

Koplan JP, Bond TC, Merson MH, et al.(2009). 'Towards a common definition of global health'. Lancet;373(9679):pp. 1993-1995. doi:10.1016/s0140-6736(09)60332-9

Maluka, S.O. (2013). 'Why are pro-poor exemption policies in Tanzania better implemented in some districts than in others?' International Journal for Equity in Health; 12 (80),pp.1-9

Masinguzi, C., Namale, L., Rutebemberwa, E., Dahal, A., Nahirya-Ntege, P., \& Kekitiiwa, A. (2018). 'The relationship between leadership style and health worker motivation, job satisfaction and teamwork in Uganda'. Journal of Healthcare Leadership;10,pp. 21-32

Mkoka, D.A., Kiwara, A., Goicolea, I., \& Hurtig, A. (2014). 'Governing the implementation of Emergency Obstetric Care: experiences of Rural District Health Managers, Tanzania'.BMC Health Services Research, 14(333), pp.1-12

MoHS (2018). National Integration Supportive Supervision Report. Ministry of Health \& Sanitation

MoHS (2015). Health Sector Recovery Plan (2015-2020). Sierra Leone: Ministry of Health \& Sanitation

Mulenga, R.M., Nzala, S., \& Mutale, W. (2018). 'Establishing common leadership practices and their influence on providers and service delivery in selected hospitals in Lusaka province, Zambia'. Journal of Public Health in Africa; 9(823),pp. 200-207

Northouse, P. G. (2010). Leadership: Theory and practice (5th ed.). Los Angeles, CA: Sage.

Nzinga, J., Mbaabu, L., \& English, M. (2013). 'Service delivery in Kenyan district hospitals -What can we learn from literature on mid-level managers?' Human Resources for Health;11(10), pp.1-10.

O’Neil, M.L. (2008). 'Human resource leadership: The key to improved results in health'. Human Resources for Health, 6(10), pp.1-4 doi:10.1186/1478-4491-6-10

Ozuruoke, A.A., Pac, O. \& Musa, A. (2011). 'Leadership Style and Business Educators' Job Performance in Senior Secondary Schools in a Changing Environment'. Journal of Educational and Social Research,1(3), pp.149155

Panda, B., Thakur, H.P., \& Zodpey, S.P. (2016). 'Does decentralization influence efficiency of health units? A study of opinion and perception of health workers in Odisha'. BMC Health Services Research, 16(6), pp. 3041 doi:10.1186/s12913-016-1786-7

Prashanth, N., Marchal, B., Devadasan, N., Kegels, G., \& Criel, B.(2014). 'Advancing the application of systems thinking in health: A realist evaluation of a capacity building programme for district managers in Tumkur, India'. Health Research Policy and Systems;12(42), pp. 1-19.

Segall, M.(2003). 'District health systems in a neoliberal world: A review of five key policy Areas'. International Journal of Health Planning \& Management; 18(1), pp.S5-26.

Shamaki (2015). 'Influence of Leadership Style on Teacher's Job Productivity in Public Secondary Schools in Taraba State, Nigeria'. Journal of Education and Practice; 6(10), pp.200-203

Tetui, M., Coe, A., Hurtig, A., Bennett, S., Kiwanuka, S.N., George, A., \& Kiracho, E.E. (2017). 'A participatory action research approach to strengthening health managers' capacity at district level in Eastern Uganda'. Health Research Policy and Systems , 15(2)110, pp.39-73. doi: 10.1186/s12961-017-0273-x

WHO (1988). The challenge of implementation: District health systems for primary healthcare. 
Geneva: Horld Health $\quad$ Organization. $\quad$ Retrieved: from https://apps.who.int/iris/bitstream/handle/10665/62369/WHO_SHS_DHS_88.1_Rev.1.pdf?sequence=1\&is Allowed $=\mathrm{y}$

WHO (2007). Towards better leadership and management in health: Report on an international consultation on strengthening leadership and management in low-income countries, Making health systems work: working paper no 10. Geneva:World Health Organization.

Willis-Shattuck, M., Bidwell, P., Thomas, S., Wyness, L., Blaauw, D., \& Ditlopo, P.(2008). 'Motivation and retention of health workers in developing countries: A systematic review'. BMC Health Services Research;8:247. doi:10.1186/1472-6963-8-247 